\title{
Toward Participatory Design: The Head and the Heart Revisited
}

\author{
Joan Greenbaum \\ Computer Science Department/Aarhus University, Denmark \\ Computer Information Systems Department/ LaGuardia Community \\ College City University of New York (on leave)
}

December 1991

\begin{abstract}
Participatory design is a movement among system developers to encourage active participation in the design process by people using computer systems. Participatory design is not one set of methods or beliefs, but rather an approach that tries to borrow practices from other areas and apply them to the workplace in order to enable people to speak out about their needs. This article discusses some of the basic ideas and their relationship to the women's movement.
\end{abstract}

\section{Focus on People in the Workplace}

Participatory design is many things to many people. Arising out of the movement for user-centered design in the 1980's, participatory design is not one set of ideas or methods. Rather it is an attempt to build a bridge which links people who are using computers in their workplace with computer systems developers, who until recently stood as experts on the other side. Perhaps it's most common element is the fact that it's built on the premise that activities in the workplace are social and that computer systems need 
to support the way people work and the way they interact. Imbedded in this essential building block are the ideas that: computer systems need to be better suited to the actual skills and working practices of the people using the systems; that work is a social activity involving the interaction of many groups of people; and that barriers between technical specialists and other working people need to be broken down in order to build effective communication between those using the products of design and those who develop and maintain them (Greenbaum, forthcoming).

While these ideas represent the ideals toward which participatory design might be built, in reality it is more like a movement of people who are striving to make the world of computer system development more focused on actively involving people in the process called design. Like any movement it has history and roots growing out of many places, including the changes in hardware and software which have made computer systems, particularly desktop systems more accessible and more understandable to people using them. And it has also grown out of movements by people who use computers in their workplaces to have more of a say in the types of computer applications they get to use. The issue is no longer whether these workers should be involved in computer system design, but rather, how their knowledge and experience can be put to good use. As office workers have gained experience in using computers they have also gained some confidence in being able to say what they like and don't like about existing technology and procedures. What participatory design sets out to do is to build on this enabling process, helping people who use systems to actively have a voice in how things could and should be done.

This article will focus on one stream in the movement toward participatory design-the role of the women's movement in influencing practices and ideas to foster an enabling environment. In particular, I will look at the way that using a gender perspective has helped focus on the social relations of me workplace, and the ways that borrowing work group practices has helped people to begin the process of talking to each other and trying to listen and understand each other. In the movement toward participatory design there has been little fomal recognition of the role of the women's movement in establishing new ways of looking at the workplace. This article can't begin to cataogue the extensive and imaginative ways this has come about. Rather it attempts to start a process where we can review some of our own history 
and find ways to enable computer users to participate more in the design process.

\section{The 'Personal is Political'}

I didn't know you had that problem too! I thought I was the only one here who had trouble printing out her files.

( secretary to administrative assistant during workshhop sesion)

The phrase, 'the personal is political' was often heard during the late 1960's and early '70's in women's groups in the United States. In small groups all across the country, often in sessions that became known as 'consciousness raising' groups, women met and told stories about the problems that they had and the way they felt those things were only happening to them. Many women, for example, thought that they were the only ones that felt frustrated at home with small children-that in fact it was their 'personal' problem and that they couldn't do anything about. It was a time of awakening, at least in a public sense, as women began to realize that the isolation they felt in their homes, or often in their dead-end jobs was an isolation that did not have to be there. As in any political movement or struggle the fact that people could join together and find out about their common problems gave rise to a new forrn of power-the power to recognize their own problems as important and the building of groups to begin to do something about it. Thus the 'personal'-those issues previously seen as small or unimportant-was placed on the agenda of the 'political'-issues that could be placed center stage and fought for.

The same things are beginning to happen in workplaces when strategies like workshops and activity groups are applied to workplace issues (Green, Owen \& Pain, 1991). Like the early women's movement it's not yet a wide-spread phenomena, but rather a series of things, called different names in different situations, which can lead toward enabling people to find their common problems within the world of the workplace. In the area of computer system design, for example, using group workshops is becoming an important part of participatory design ( Kensing and Madsen, 1991). 
As a way of illustrating how this is done, I'll introduce some activities that I took part in as a consultant in a participatory design project. In a recent project for a large non profit organization in New York, we used a series of workshops to foster an environment where staff members from different departments would begin to express their ideas about what types of hardware and software they wanted when a new desktop office system was installed (Greenbaum \& Madsen, forthcoming, 1992). While management's interest in the project was to establish specifications for the new system, we as computer consultants chose to use participatory strategies in order to get people from different departments to learn more about what was happening in the workplace. We began by asking heads of each department to involve people with the most day-to-day experience using existing software. Twelve staff members ranging in titles from data entry clerk and secretary to editorial assistant and area coordinators were recommended or volunteered themselves for the workshops. As part of the workshop process, the participants were excused from the normal work during the workshop sessions.

For the first workshop, which we balled a Storytelling session, the participants were asked to prepare two short oral stories about their worst and most successful use of computers in their daily work. One of the stories told by staff member, was about the day she ended up spending two hours trying to print out a letter. She had gone from PC to PC running into all sorts of problems, like lack of the right size disk drive, lack of memory and incompatible printers. As this 'nightmare' scenario began to unfold it became clear that her problem was often encountered by others; everyone had just been too embarrassed or felt too inept to tell others that this was happening to them. This lack of confidence in one's ability to handle technical problems is a problem, for the language of most workplaces is so often technocentric that workers, both men and women, are left with the feeling that the problem is theirs not the system's. The Storytelling workshop helped to break down some of these barriers, and the project then went on to a series of Future Workshops (Kensing \& Madsen,1991) that used group strategies to help people talk about problems (Critique workshop), dream about alternative ways of doing things (Fantasy phase) and plan for how to bring their problems and ideas to management's attention (Implementation workshop). The workshops were half day sessions held over a period of two months, and participants found them so useful that they were interested in continuing the process. 
As in many computer consulting projects, management's objectives are often different and sometimes contradictory from those of the office workers effected by the system. Traditionally the systems developer, by training and by contractual agreement is the agent of management in developing specifications for a new system. By advocating a participatory approach in the project mentioned above, we were able to convince management that not only would the specifications be more realistic as a result of a workshop process, but the enhanced communication in the office would set the stage for a better working environment (Greenbaum \& Madsen, forthcoming). As it turned out, management was pleased with me outline of specifications that grew out of the workshops, but extremely enthusiastic about the group process. In fact in many ways, the process, (workshops) seemed to take on more importance than the product (specifications).

The workshop story illustrated here is not a unique incident. While participatory design, in some ways grows out of the Scandinavian approach to systems design, the idea of involving users is beginning to take hold in the United States. At the Participatory Design Conference in Seattle (PDC '90) computer system developers exchanged stories about what how they organized their projects. A common theme was the use of workshops to enable workers to get actively involved in the design process. In Los Angles at the Computer Supported Cooperative Work Conference (CSCW '90), a 'birds of a feather' session on participatory design drew more than thirty designers together to talk about their growing use of small group collaborative methods. And at the ACM Computer-Human Interaction Conference in New Orleans (CHI'91) a plenary session was held on the topic. With wide ranging audience participation, developer after developer got up to share their stories about how they use workshops to foster a more participatory environment for computer users. As in the early days of the women's movement, computer system developers like the computer users they are trying to empower are beginning to find out that they are not isolated in their problems and issues. For computer systems developers, like other office workers, the 'personal' (their way of organizing projects) is also beginning to become 'political'. 


\section{Integrating Emotional and Intellectual La- bor}

Traditionally, systems development has been a field that dealt in abstractions. People who work as computer system developers, systems analysts and computer specialists are trained to focus on finding the 'right' solution to each computer problem. Using tools like data flow diagrams, flowcharts and network models they are taught to examine the flow of data through a system, turning work practices into procedures and information into quantifiable data. This training, and indeed the large body of literature that supports the management of information systems development, focuses on separating the people in the workplace from the things that they do (Greenbaum \& Kyng, 1991). It is as if the people, with their feelings, ideas and energy are pushed to the side as supposedly more objective issues like data take on more significance.

Eveylen Fox Keller (1985) wrote about this process in the natural sciences. She argued that:

The most immediate issue for a feminist perspective on the natural sciences is the deeply rooted popular mythology that casts objectivity, reason and mind as male and subjectivity, feeling and nature as female. In this division of emotional and intellectual labor, women have been the guarantors and protectors of the personal, the emotional, the particular, whereas science-the province par excellence of the impersonal, the rational and the general-has been the preserve of men.

Keller's point is that this artificial split of emotional from intellectual labor has negatively effected the natural sciences so that their attention to presumably objective issues is at the expense of the emotional and human aspects of the natural environment. In an article entitled The Head and the Heart (Greenbaum, 1987,1990), I applied Keller's perspective to the area of computer system development, outlining how systems development methodology borrowed heavily from the natural sciences, while largely ignoring the social aspects of the workplace.

The attempts to balance this view are evolving into what we now call partic- 
ipatory design. Of course, participatory design in and of itself can't tip the scales in the direction of those emotional and social values that Keller says women have been the protectors of. But paticipatory or as it is sometimes called, cooperative design, asks systems developers to put three issues in the forefront of their efforts. They are:

- focusing on the whole workplace and the actual practices of the people doing the work;

- involving office workers at all levels in articulating their needs and expressing their concerns for what kinds of computer support they may need; and

- developing new methods that help system developers and office workers actively support ongoing social processes.

System developers have been able to learn a good deal from the humanities and the social sciences in order to focus on the first area, that of viewing the workplace as a whole, rather than the sum of its quantifiable parts (Greenbaum \& Kyng, 1991). But the extent to which participatory design can be successful in bridging the gap between the intellectual world of design and the emotional arena of the workplace, is dependent on the ways system developers can learn to actively involve people in the process and develop and borrow methods that accomplish this. As briefly illustrated in the last section, workshops serve as vehicles that can help people feel more adequate about what they have to say, gaining confidence as they hear others confront the same problems. When systems developers act as facilitators instead of authoritative experts, they stand a better chance of crossing this bridge. One of the main stumbling blocks to involving people in the design process has been the 'expert' and indeed technocentric language that developers use. This language, like much of the culture of workplaces, divides this world into things versus people (Bødker \& Greenbaum, forthcoming). And in this process it is the people, particularly entry-level and lower level workers who often feel inadequate in their ability to understand let alone confront experts who tell them about things that threaten their intellectual and emotional world.

Over the last two decades the area of workshop facilitation has played an important role in the caring professionals, particularly in mental health and 
group dynamics settings. As system developers learn to borrow from these fields, and as they continue to learn from the social sciences, the chance of building methods that actively support and encourage human development in the office environment, emerge. Systems developers using participatory design strategies as tools of empowerment could help integrate the fragmented lives we lead in the workplace. But this means changing systems developers from being the keepers of the technocentric gate to being facilitators for change. And that is a process, like that of the women's movement, that will take many decades, require building many alliances, and hopefully will tear down some of the walls of isolation and build confidence for people in the workplace.

\section{Acknowledgements:}

I want to thank Susanne Bødker for her ideas and help. Some of the ideas discussed here are elaborated on more fully in a forthcoming chapter that we did together for Gender, Information Technology and the Design of Office Systems, Green, Owen \& Pain (eds). I also want to thank Kim Halskov Madsen for his energy and ideas in carrying out the Paticipatory Design project, upon which part of this article is based. The original inception of the Head and the Heart (1987) grew out of my collaboration in Aarhus, Denmark, with Randi Markussen and Gitte Møldrup Nielsen, and was inspired by their encouragement.

This article will be forthcoming in Lechto, A.M. \& Eriksson, I. (eds) (1992) Women Work and Computerization, North-Holland. It was prepared as a keynote address to the IFIP 9.1 Conference, Women, Work and Computerization, July 199 I, Helsinki, Finland.

\section{References}

Bødker, Susanne, and Greenbaum, Joan,(forhcoming) "Design of Information Systems - Things vs. People", in Green, Owen and Pain (eds), Gender, Information Technology and the Design of Office Systems. 
Fox-Keller, Evelyn, (1985) Reflections on Gender and Science (Yale Univ. Press, 1985).

Green, Eileen, Owne, Jenny and Pain, Den, (1991) "Developing computerised Office Systems: a Gender Perspective in UK Approaches" in Women, Work and Computerization, Lehto, Eriksson, (eds).

Greenbaum, Joan (1990) "The Head and the Heart", Computers and Society, Vol. 20, No. 2, (ACM) June; previously appeared as Computer Science Department Publication, Aarhus University, (1987).

Greenbaum, Joan, and Kyng, Marten, eds. (1991) Design at Work: Cooperative Design of Computer Svstems, (Erlbaurn Assoc, Hillsdale, N.J.).

Greenbaum, Joan (forthcoming) "A Design of One's Own: Toward Participatory Design in the US", in Participatory Design, Namioka, Aki, and Schuler, Douglas (eds), (Erlbaum Associates, Hillsdale, N.J)

Greenbaum, Joan and Madsen, Kim Halskov (forthcoming) "Small Changes", in Namioka and Schuler, Op. Cit.

Kensing, Finn, and Madsen, Kim Halskov "Generating Visions: Future Workshops and Metaphorical Design", in Greenbaum and Kyng, Op. Cit. 